\title{
Forensische geneeskunde in het medisch onderwijs; een eerste opzet
}

\author{
U.J.L. Reijnders, M.B.M. Soethout, G. van der Wal
}

\begin{abstract}
Samenvatting
Inleiding: Praktiserend artsen hebben onvoldoende kennis van forensisch geneeskundige onderwerpen en in het medisch onderwijs in Nederland krijgen deze onderwerpen onvoldoende aandacht. Toch krijgt iedere arts in de praktijk te maken met forensisch geneeskundige aspecten.Dit artikel bespreekt de opzet van en de ervaringen met een nieuwe cursus forensische geneeskunde in het basiscurriculum van het Vrije Universiteit-Medisch Centrum $(V U-M C)$.
\end{abstract}

Cursusopzet: Het forensisch geneeskundig onderwijs bestaat uit een hoorcollege en een hoofdstuk in de syllabus van het blok Gezondheidszorg in jaar 4, en een werkgroep en schouwonderwijs in jaar 5.

Evaluatie: Wij vergeleken de resultaten op een kennistoets over forensische geneeskunde van twee groepen studenten: studenten die forensisch onderwijs aan het VU-MC gevolgd hadden en studenten die geen forensisch onderwijs genoten hadden. Na afloop van de werkgroep forensische geneeskunde vulden de studenten die deelgenomen hadden een evaluatieformulier in.

Resultaten: De studenten die forensisch geneeskundig onderwijs gevolgd hadden, scoorden over het algemeen hoger op de toets dan de studenten die dergelijk onderwijs niet gevolgd hadden. De evaluatie leverde gemiddelde scores op die niet meer dan 1.2 punt (op een vijfpuntsschaal) verschilden van de maximale score.

Discussie/conclusies: Onderwijs over forensische geneeskunde lijkt te resulteren in een verbeterd kennisniveau. De beoordeling door de studenten van het onderwijs is positief. Toch is er nog genoeg ruimte voor verdere verbetering. Verder onderzoek naar de effecten van het onderwijs in de forensische geneeskunde is gewenst. Het is belangrijk dat forensisch geneeskundig onderwijs wordt opgenomen in de geneeskundige basiscurricula, vervolgopleidingen en nascholingsprogramma's. (Reijnders UJL, Soethout MBM, Wal G. van der. Forensische geneeskunde in het medisch onderwijs; een eerste opzet. Tijdschrift voor Medisch Onderwijs 2002;21(5):222-227.)

\section{Inleiding}

De forensische geneeskunde houdt zich bezig met medische zaken op het grensvlak van recht, rechtshandhaving en gezondheidszorg. Hieronder wordt onder andere verstaan het maken van onderscheid tussen een natuurlijke en een nietnatuurlijke dood. Daartoe is kennis nodig van de lijkschouw en van postmortale verschijnselen in het bijzonder. Verder vallen onder forensische geneeskunde zaken als zedendelicten, geweld, mishandeling en letsels die daaruit ontstaan.

Alle behandelend artsen krijgen in de beroepsuitoefening met forensisch geneeskundige aspecten te maken. In de dagelijkse praktijk blijkt echter dat er lacunes zijn in de kennis van artsen op dit gebied. Om deze lacunes in kaart te brengen is in 1999 een toets over forensisch geneeskundige aspecten afgenomen bij een groep van 110 huisartsen, medisch specialisten en 
arts-assistenten en een groep van 93 vierdejaars geneeskundestudenten die geen onderwijs over forensische geneeskunde hadden genoten. ${ }^{1}$ Uit de resultaten van deze toets bleek dat de kennis van artsen en studenten met betrekking tot de forensische geneeskunde tekorten vertoonde. Tevens werd duidelijk dat de groep praktiserend artsen op een aantal essentiële onderdelen, bijvoorbeeld de afhandeling van overlijdensgevallen, slechter scoorde dan de groep medisch studenten. Ook eerder werd al gewezen op de noodzaak van onderwijs in forensische geneeskunde in de medische opleiding. ${ }^{2}$ In de eindtermen van het Raamplan 2001 artsopleiding zijn in het hoofdstuk over aspecten in relatie tot de maatschappij en het gezondheidszorgsysteem aspecten van de forensische geneeskunde opgenomen, met name het vaststellen van een natuurlijke en niet-natuurlijke dood. ${ }^{3}$

$\mathrm{Om}$ in de gesignaleerde leemte in de geneeskundeopleiding te voorzien heeft de Afdeling Sociale Geneeskunde van het Vrije Universiteit-Medisch Centrum (VUMC) in 1999 een onderwijsprogramma forensische geneeskunde ingevoerd. Hiermee is de medische opleiding aan het VU-MC de eerste in Nederland die onderwijs in de forensische geneeskunde structureel heeft opgenomen in het medisch basiscurriculum. ${ }^{1}$ In dit artikel wordt dit onderwijs beschreven en worden de eerste evaluatieresultaten gepresenteerd.

\section{Cursusopzet}

Gesteund door de resultaten van het eerder genoemde onderzoek is een cursus forensische geneeskunde in het basiscurriculum van de artsopleiding aan het VU-MC opgenomen. ${ }^{1}$ De globale kennisdoelen van deze cursus houden in dat de student bekend gemaakt wordt met:

- forensisch geneeskundige begrippen, definities en omschrijvingen;
- taken van de forensisch geneeskundige; - forensisch geneeskundige aspecten waarmee iedere arts geconfronteerd kan worden;

- tweedelijns forensisch geneeskundige specialismen;

- het verschil tussen natuurlijke en nietnatuurlijke dood en de zin van het schouwen van lijken;

- verschillende vormen van zedenmisdrijven;

- de begrippen geweld en mishandeling en letsels die daaruit kunnen voortkomen;

- relevante wetenswaardigheden rondom de begrippen behandelend geneeskundige, lijkbezorging en sectie.

Als vaardigheidsdoel is gesteld dat studenten in staat moeten zijn uiteenlopende, aan de praktijk ontleende, forensisch-geneeskundige casus op te lossen.

In september 1999 is in het vierde jaar gestart met een hoorcollege forensische geneeskunde. In de syllabus van het blok Gezondheidszorg is een hoofdstuk over forensische geneeskunde opgenomen. Sinds januari 2000 worden in het vijfde en zesde jaar van de opleiding in het kader van het zogenaamde Stage Overstijgend Onderwijs verplichte werkgroepen gegeven, waaronder een werkgroep forensische geneeskunde in jaar 5. Hierbij vindt gedurende een dagdeel een multidisciplinaire, klinische verdieping plaats van enkele thema's. In het eerste deel van deze werkgroep wordt aan de hand van foto's en casuïstiek in groepjes van drie tot vier studenten geoefend met de beoordeling en afhandeling van sterfgevallen. Vervolgens worden de casus door de studenten geëvalueerd in de totale groep van ongeveer veertig studenten. De forensisch geneeskundige wordt hier bijgestaan door een huisarts, die eventuele aanvullingen geeft vanuit de dagelijkse praktijk. In het tweede deel van de werkgroep komen onderwerpen als zeden- 
delicten, geweld, (kinder)mishandeling en daaruit ontstane letsels aan de orde. Tijdens deze sessie levert een kinderchirurg of kinderarts een bijdrage. De totale sessie neemt drie uur in beslag. Ten slotte is sinds september 2000, in samenwerking met de Afdeling Pathologie, aan het begin van het vijfde jaar van de artsopleiding in het kader van het 'obductieonderwijs' zogenaamd schouwonderwijs toegevoegd. Daarin neemt de forensisch geneeskundige met studenten naast een overledene plaats om de volledige lijkschouw uit te voeren. Ook wordt aandacht besteed aan beoordeling en bepaling van de doodsoorzaak op basis van patiëntengegevens, de heteroanamnese en de interpretatie van omgevingsfactoren. Als laatste onderdeel wordt de invulling van het B-doodsoorzakenformulier behandeld. Eerder onderzoek gaf aan dat praktisch onderwijs omtrent het invullen van het B-doodsoorzakenformulier bijdraagt aan de kwaliteit van de informatie in het ingevulde formulier. ${ }^{4}$

\section{Evaluatie}

\section{Methode}

\section{Toets}

In de periode van januari tot en met oktober 2000 hebben de eerste 100 studenten die de forensisch geneeskundige werkgroep tijdens het Stage Overstijgend Onderwijs volgden in aansluiting op de werkgroep een toets gemaakt. Deze groep studenten had het hierboven beschreven 'schouwonderwijs' niet gevolgd, omdat dit pas in september 2000 van start ging. De toets bestond uit 29 twee-, drie- en vierkeuzevragen. Dezelfde toets was in 1999 in een onderzoek voorgelegd aan 93 vierdejaarsstudenten die geen forensisch geneeskundig onderwijs gevolgd hadden. ${ }^{1}$ Er werd een vergelijking gemaakt tussen de toetsresultaten van de groep studenten die deelnam aan het onderzoek in 1999 en de groep studenten die het nieuwe programma aan het VU-MC volgde. Voor de beoordeling werden de vragen ingedeeld in zes categorieën:

1. Algemene vragen (6)

2. A- en B-overlijdensverklaringen en de Wet op de lijkbezorging (7)

3. Natuurlijke en niet-natuurlijke dood (9)

\section{Lijkschouw (3)}

5. Zedendelicten (2)

6. Mishandeling, geweld, letsels (2)

Per vraag werd voor beide groepen studenten het gemiddelde percentage correcte antwoorden (met standaarddeviatie) berekend. Op basis hiervan werd voor beide groepen het percentage correct beantwoorde vragen per categorie berekend. Het verschil tussen de scores van beide groepen studenten werd geanalyseerd met behulp van een t-toets waarbij $\mathrm{p}<0.05$ als significant werd beschouwd.

\section{Vragenlijst}

In dezelfde periode in 2000 waarin 100 studenten deelnamen aan de kennistoets kregen alle studenten $(n=147)$ na afloop van de werkgroep forensische geneeskunde een evaluatieformulier uitgereikt over inhoud, organisatie en kwaliteit van het forensisch geneeskundig onderwijs. 134 ingeleverde vragenformulieren werden beoordeeld. De vragen dienden beantwoord te worden op een vijfpuntsschaal. Per vraag werden de gemiddelde score en de standaarddeviatie berekend. Tevens was er ruimte voor algemene opmerkingen.

\section{Resultaten}

\section{Toets}

In alle categorieën bleken de studenten die de cursus forensische geneeskunde gevolgd hadden, hoger te scoren dan de studenten die dergelijk onderwijs niet ge- 
volgd hadden (tabel 1). Worden de percentages goede antwoorden per vraag bekeken, dan blijkt de groep studenten die forensisch onderwijs volgde op 24 vragen hoger, op één vraag gelijk en op vier vragen lager te scoren dan de studenten die geen forensisch onderwijs volgden. Bij zestien van de 24 vragen met een hogere score in de groep met forensisch onderwijs was het verschil tussen beide groepen statistisch significant; bij de vragen waarop de groep die forensisch onderwijs gevolgd had, lager scoorde, waren de verschillen niet statistisch significant.

Tabel 1. Resultaten op een kennistoets over forensisch geneeskundige onderwerpen van een groep vierdejaars studenten ( $N=93)$ die geen forensisch onderwijs had gevolgd en een groep vijfdejaars studenten $(N=100)$ die een nieuw programma forensisch onderwijs volgde.

\begin{tabular}{lcccc}
\hline Categorie & \multicolumn{3}{c}{ Percentage goede antwoorden } \\
\hline & $\begin{array}{c}\text { Geen forensisch onderwijs } \\
(\mathrm{N}=93)\end{array}$ & \multicolumn{2}{c}{$\begin{array}{c}\text { Wel forensisch onderwijs } \\
(\mathrm{N}=100)\end{array}$} \\
& gemiddelde & $\begin{array}{c}\text { standaard- } \\
\text { deviatie }\end{array}$ & gemiddelde & $\begin{array}{c}\text { standaard- } \\
\text { deviatie }\end{array}$ \\
\hline Algemeen & 53 & 22 & 62 & 25 \\
$\begin{array}{l}\text { A- en B-overlijdensverklaringen } \\
\text { en de Wet op de lijkbezorging }\end{array}$ & 42 & 16 & 66 & 22 \\
$\begin{array}{l}\text { Natuurlijke en niet-natuurlijke } \\
\text { dood }\end{array}$ & 45 & 29 & 68 & 28 \\
Lijkschouw & 68 & 14 & 74 & 18 \\
$\begin{array}{l}\text { Zedendelicten } \\
\text { Mishandeling, geweld en letsels }\end{array}$ & 74 & 17 & 82 & 7 \\
\hline
\end{tabular}

Tabel 2. De gemiddelde score en standaarddeviatie (sd.) per evaluatievraag op verschillende vijfpuntsschalen.

\begin{tabular}{|c|c|c|}
\hline \multirow[t]{2}{*}{ Vraag } & $\begin{array}{l}\text { gemiddelde } \\
\text { score }\end{array}$ & sd. \\
\hline & \multicolumn{2}{|c|}{$\mathrm{N}=134$} \\
\hline & \multicolumn{2}{|c|}{$1=$ zeer oneens, $5=$ zeer eens } \\
\hline $\begin{array}{l}\text { Het is mij duidelijk geworden waarom dit thema/onderwerp in de } \\
\text { studie is opgenomen. }\end{array}$ & 4.3 & 0.63 \\
\hline $\begin{array}{l}\text { Het thema/onderwerp van deze bijeenkomst sloot goed aan op } \\
\text { mijn tot dan toe opgedane kennis en ervaring. }\end{array}$ & 3.8 & 0.75 \\
\hline \multirow{2}{*}{$\begin{array}{l}\text { De gebruikte onderwijsmethode (demonstratie, werkgroep, college, } \\
\text { nabespreking, enz.) vond ik voor dit onderdeel geschikt. }\end{array}$} & 4.1 & 0.58 \\
\hline & \multicolumn{2}{|c|}{ 1=te laag, 5=te hoog } \\
\hline \multirow[t]{2}{*}{ Het niveau van deze bijeenkomst was: } & 3.0 & 0.24 \\
\hline & \multicolumn{2}{|c|}{$1=$ te weinig, $5=$ te veel } \\
\hline De voor de bespreking van dit onderdeel beschikbare tijd was: & 2.9 & 0.55 \\
\hline
\end{tabular}




\section{Vragenlijst}

De grootste afwijking van de gemiddelde scores op de vragenlijst ten opzichte van de gunstigste score bedraagt 1.2 punten (tabel 2). Bij de algemene opmerkingen werd genoemd dat het duidelijk is dat forensisch geneeskundig onderwijs in de studie is opgenomen, dat kennis over de afhandeling van een overlijdensgeval nuttig is, en dat gebruik van beeldmateriaal en casuïstiek bij uitstek leerzaam is. $\mathrm{Er}$ werd met name gepleit voor meer aandacht voor forensische geneeskunde in de opleiding.

\section{Discussie}

Uit eerder onderzoek is gebleken dat er behoefte bestaat aan forensisch geneeskundig onderwijs. ${ }^{12}$ Deze behoefte wordt nog onderstreept door eindtermen in Raamplan 2001 betreffende forensische aspecten. ${ }^{3}$ De resultaten van het onderzoek dat in dit artikel beschreven wordt, wijzen uit dat een groep studenten die een cursus over dit onderwerp aan het VU-MC volgde, hoger scoort op een kennistoets over forensische geneeskunde dan een groep studenten die geen onderwijs over dit onderwerp gekregen had. Ondanks het feit dat het niet dezelfde groepen medisch studenten betreft, vormt dit resultaat een aanwijzing dat het onderwijs vruchten afwerpt. De beoordeling door de studenten van de inhoudelijke aspecten en de organisatie van het forensisch geneeskundig onderwijs aan het VU-MC is positief.

Hoewel de resultaten van de evaluatie van de cursus aan het VU-MC hoopgevend zijn, is een aantal kritische opmerkingen op zijn plaats. In dit onderzoek zijn twee verschillende groepen studenten vergeleken. De studenten die geen forensisch onderwijs gevolgd hadden, waren vierdejaars studenten die nog geen enkele praktijkervaring hadden. De groep die het onderwijs aan het VU-MC gevolgd had, bestond uit vijfdejaars co-assistenten. Hoewel de onderzoeksresultaten erop wijzen dat het kennisniveau na het onderwijs verbeterd is, zijn de scores op de kennistoets van dien aard dat er nog voldoende ruimte overblijft voor verdere verbetering. Hierbij moet opgemerkt worden dat de effecten van het obductieonderwijs in het vijfde jaar niet bijdroegen aan het toetsresultaat, omdat de studenten in de onderzoeksgroep dit onderwijs niet gevolgd hadden. De beheersing van forensisch-geneeskundige vaardigheden is niet getoetst.

Een complicerende factor is dat net afgestudeerde artsen straks in de praktijk in aanraking komen met artsen die zelf onvoldoende kennis van deze materie hebben. Dit betekent dat afgestudeerde artsen niet terug kunnen vallen op hun ervaren collegae. Eerder zal de omgekeerde situatie van toepassing zijn. Behandelend artsen zullen te rade moeten gaan bij hun jongere collegae die wel forensisch geneeskundig onderwijs hebben genoten. Behalve aan het VU-MC wordt in de overige medische faculteiten momenteel nog niet op gestructureerde wijze aandacht besteed aan de forensische geneeskunde. Van belang is dat alle medische faculteiten forensisch geneeskundig onderwijs in het basiscurriculum opnemen. Ook zal in nascholingsprojecten van huisartsen (hetgeen overigens al volop gebeurt), verpleeghuisartsen en medisch specialisten meer aandacht moeten worden besteed aan dit vakgebied. De impact van dit onderwijs voor de praktijk zal pas in een later stadium onderzocht kunnen worden.

\section{Conclusies}

De in dit artikel beschreven evaluatie van het forensisch geneeskundig onderwijs aan het VU-MC geeft aanwijzingen dat het gegeven onderwijs de kennis van de studenten over dit onderwerp doet toenemen en dat studenten tevreden zijn over het 
onderwijs. Niettemin moet het forensisch onderwijs verder verbeterd worden. Het verdient aanbeveling om in een vervolgonderzoek de effecten van het volledige programma forensisch geneeskundig onderwijs te toetsen.

\section{Literatuur}

1. Reijnders UJL, Das C, Soethout MBM, Wal G van der. Artsen herkennen niet-natuurlijke dood onvoldoende. Medisch Contact 1999;54:1704-7.

2. Reijnders UJL, Soethout MBM, Wal G van der. De noodzaak van forensische geneeskunde in het medisch onderwijs. In: Werkgroep GOC99, redactie. Programmaboek 9de Gezond Onderwijs Congres. Nederlandse Vereniging voor Medisch Onderwijs; 1999.

3. Metz JCM, Verbeek-Weel AMM, Huisjes HJ, Raamplan 2001 artsopleiding, bijgestelde eindtermen van de artsopleiding. Nijmegen: Mediagroep Nijmegen; 2001.
4. Wendte JF, Broer J, Bijlsma F. De kwaliteit van de aangifte van doodsoorzaken. Getrainde medische studenten vergeleken met praktiserende artsen. Tijdschrift voor Gezondheidswetenschappen 1998; 76:263-6.

\section{De auteurs:}

Dr. U.J.L. Reijnders, forensisch geneeskundige, GG\&GD Amsterdam.

Drs. M.B.M. Soethout, onderwijscoördinator, Afdeling Sociale Geneeskunde, VU-MC.

Prof. dr. G. van der Wal, hoofd Afdeling Sociale Geneeskunde, $V U-M C$.

Correspondentieadres:

Dr. U.J.L. Reijnders, GG\&GD Amsterdam, Postbus 2200, 1000 CE Amsterdam, tel.: 020-5555513, fax: 0205555106,ureijnders@gggd.amsterdam.nl.

\section{Summary}

Introduction: Medical practitioners have insufficient knowledge of forensic medicine and too little attention is being paid to this subject in undergraduate medical education. Nevertheless, every medical practitioner is likely to be confronted with aspects of forensic medicine in day-to-day medical practice. This paper presents a description and a first evaluation of a course on forensic medicine in the undergraduate medical curriculum of the Vrije Universiteit Medical Centre (VU-MC), Amsterdam, the Netherlands.

Course design: The forensic medicine course consists of a lecture and a chapter in the Health Care syllabus in year 4 , and a working group and post mortem examination training in year 5.

Evaluation: We compared the results on a knowledge test of students who had followed the VU-MC forensic medicine course and students who had not received any teaching in forensic medicine. Following the forensic medicine course students completed an evaluation form.

Results: The students who had followed the forensic medicine course obtained higher scores on the knowledge test compared with the students without training in forensic medicine. Regarding the evaluation form, the greatest difference between the mean scores and the optimal scores was 1.2 points (on a five point scale).

Discussion/conclusion: The results indicate that the forensic medicine course improves students' knowledge. Students appear to appreciate the course. Nevertheless there remains room for improvement. Further studies should address the effects of the full forensic medicine course. It is important that forensic medicine be incorporated into the undergraduate core curriculum as well as postgraduate and continuing education programmes. (Reijnders UJL, Soethout MBM, Wal G van der. A new forensic medicine course in undergraduate medical education. Dutch Journal of Medical Education 2002;21(5):222-227.) 